\title{
Apropriação da terminologia 'uso consciente de medicamentos' visando à promoção da saúde global
}

\author{
Appropriation of the terminology 'conscious use of medicines' aiming the \\ improvement of global health
}

\section{Apropiación de la terminología 'uso consciente de medicamentos' para la promoción de la salud global}

Maria Fernanda Turbay Palodeto ${ }^{1, a}$

mariafernandatp@yahoo.com.br | http://orcid.org/oooo-0002-4514-2585

Marta Luciane Fischer ${ }^{1, b}$

marta.fischer@pucpr.br | http://orcid.org/0000-0002-1885-0535

${ }^{1}$ Universidade Católica do Paraná, Programa de Pós-Graduaçã̃o em Bioética. Curitiba, PR, Brasil.

a Mestrado em Bioética pela Universidade Católica do Paraná.

${ }^{\text {b }}$ Doutorado em Zoologia pela Universidade Federal do Paraná.

\section{Resumo}

A inserção dos medicamentos nas práticas de consumo consciente representa um potencial de aliada na promoção da saúde global; assim, objetivou-se mapear a aplicação da terminologia uso consciente de medicamentos. Realizou-se uma revisão documental integrativa quantitativa com a categorização de 124 textos científicos e 400 conteúdos digitais. Os resultados atestaram incompatibilidade de sinonímia com a terminologia uso racional de medicamentos, uma vez que esta não contempla as dimensões econômicas, sociais, psicológicas, ambientais, de comunicação e de valores éticos na decisão de como usufruir dos medicamentos. A implementação e consolidação da terminologia deve subsidiar políticas educacionais e de comunicação e, consequentemente, a instrumentalização para a prática do autocuidado e cuidado com o outro e com o ambiente, ao ressignificar o mecanismo saúde/doença e compreender os processos envolvidos na pesquisa, produção, distribuição e descarte de medicamentos.

Palavras-chave: Autocuidado; Automedicação; Educação em saúde; Impacto ambiental; Uso de medicamentos; Terminología.

\begin{abstract}
The insertion of the medicines in the practices of conscious consumption represents a potential ally of the global health improvement; thus we searched for mapping the employment of the terminology conscious use of medicines. An integrative and quantitative documentary analysis was carried out categorizing 124 scientific texts and 400 digital contents. The results attested that its use as a synonymy for the terminology rational use of medicines is incompatible, since the latter does not contemplate the economic, social, psychological, environmental, ethical values in the moment of decision about how to use the medicines.
\end{abstract}


The implementation and consolidation of terminology may support educational and communication policies and, consequently, the instruments for achieving the self-care and the care of others and look after the environment by giving a new meaning to the health/disease mechanism and by understanding the processes involved in the researches, production, distribution and discard of medicines.

Keywords: Self-care; Self-medication; Health education; Use of medicines; Terminology.

\section{Resumen}

La inserción de los medicamentos en las prácticas del consumo consciente representa un potencial de aliada en la promoción de la salud global; así tuvimos el objetivo de mapear la aplicación de la terminología uso consciente de medicamentos. Se realizó una revisión documental integrativa cuantitativa categorizando 124 textos científicos y 400 contenidos digitales. Los resultados atestaron incompatibilidad de sinonimia con la terminología uso racional de medicamentos, ya que el último no contempla las dimensiones económicas, sociales, psicológicas, ambientales, de comunicación y de valores éticos en la decisión de cómo disfrutar los medicamentos. La implementación y consolidación de la terminología puede subsidiar políticas educativas y de comunicación y en consecuencia la instrumentación para la práctica del autocuidado y del cuidado del otro y del ambiente al dar nueva significación para el mecanismo salud/enfermedad y comprender los procesos involucrados en la investigación, producción, distribución y descarte de medicamentos.

Palavras clave: Autocuidado; Automedicación; Educación en salud; Utilización de medicamentos; Terminología.

Declaração de conflito de interesses: não há conflito de interesses.

Fontes de financiamento: bolsa de estudo concedida pela ECV-PUCPR.

Considerações éticas: a pesquisa foi autorizada pelo Comitê de Ética envolvendo Seres Humanos, CAAE 41472415.2.0000.5393 e seguiu as recomendações éticas nacionais e internacionais.

Agradecimentos/Contribuições adicionais: agradecemos o apoio da Pontifícia Universidade Católica (PUC), representada pelo Dr. Sérgio Siqueira Surugi para a realização do trabalho que fundamenta este artigo, no Programa de Pós-graduação em Bioética (PPGB), e à acadêmica de Farmácia da PUCPR e do Programa de Iniciação Científica Erica Costa dos Santos.

Histórico do artigo: submetido: 28 fev. 2018 | aceito: 21 out. 2018 | publicado: 29 mar. 2019.

Apresentação anterior: os dados do presente estudo foram utilizados, em parte, para redação da dissertação de mestrado do PPGB-PUCPR intitulada 'Apropriação do termo uso consciente de medicamentos pela bioética ambiental'.

Licença CC BY-NC atribuição não comercial. Com essa licença é permitido acessar, baixar (download), copiar, imprimir, compartilhar, reutilizar e distribuir os artigos, desde que para uso não comercial e com a citação da fonte, conferindo os devidos créditos de autoria e menção à Reciis. Nesses casos, nenhuma permissão é necessária por parte dos autores ou dos editores. 


\section{Introdução}

O uso abusivo de medicamentos constitui um problema de saúde pública de âmbito mundial ${ }^{1}$ com potencial impacto na saúde global, em escala geográfica e temporal, abrangendo igualmente esferas físicas, mentais e sociais de todos os seres vivos ${ }^{2,3}$. A automedicação concebida como um problema complexo e global, demanda a intervenção de uma ferramenta hábil na intermediação de diálogos entre os diversos atores envolvidos na busca de soluções consensuais e justas que promovam o uso consciente de medicamentos ${ }^{4}$.

A bioética se sobressai como essa almejada ferramenta devido à sua capacidade de unir conhecimentos biológicos a valores humanos em um cenário multidisciplinar gerador de conflitos de interesses de atores como a indústria farmacêutica, os consumidores, a comunidade científica e o ecossistema ${ }^{5}$. Para Potter ${ }^{6}$, a bioética como disciplina sistêmica que vislumbra a sobrevivência humana, possui dimensão global e julga como imoral qualquer ação que prejudique de alguma forma a sobrevivência. Mesmo sendo o uso de medicamentos intrinsicamente antropocêntrico, no qual plantas e animais são utilizados para o imediato benefício humano ${ }^{7}$, há necessidade de se preocupar com a preservação da vida por meio da sustentabilidade. Isto é, por meio de ações que conduzam ao desenvolvimento social, tecnológico e científico, promovendo e respeitando a biodiversidade e o ecossistema ${ }^{4}$. Desta forma, deve-se estabelecer conexão entre a ética médica e a ética do meio ambiente ${ }^{6} \mathrm{em}$ prol do exercício da saúde global. A bioética de intervenção, preconizada por Garrafa e Porto $^{8}$ como a busca de ações, preferencialmente de cunho público e coletivo, objetiva minimizar diferentes situações de vulnerabilidades às quais grande parte da população marginalizada está submetida ${ }^{9}$. $\mathrm{O}$ acesso restrito às informações e às dúvidas sobre a veracidade das mesmas, atrelado às promessas da resolução de problemas do corpo e da alma através do consumo de medicamentos, a um sistema de saúde deficiente e ao desenvolvimento de uma sociedade imediatista, egoísta, consumista e vaidosa ${ }^{10}$, são alguns dos fatores que tornam a população vulnerável9.

O medicamento não deve ser tratado como mercadoria ou bem de consumo, pois pode desencadear efeitos adversos, toxicidade e até a morte. Estudos publicados pela Organização Mundial da Saúde $(\mathrm{OMS})^{11}$, demonstram que mais de $50 \%$ dos medicamentos são utilizados ou prescritos de forma inapropriada e a metade dos consumidores não os administram corretamente. Entretanto, estes produtos são considerados elementos importantes para o cuidado da saúde, e a promoção de seu uso racional deve ser uma prioridade dos sistemas de saúde de todo o mundo ${ }^{11}$, refletido em campanhas e políticas públicas e visando à redução do consumo irrestrito de fármacos ${ }^{1}$.

A terminologia uso racional de medicamentos é caracterizada pela administração do medicamento correto para o problema de saúde devidamente diagnosticado, em dose e posologia apropriadas, durante um período de tempo e custo adequados ${ }^{12}$. A consolidação do uso desta termologia se deu em 1985, em Nairobi, Kenya, durante a Conferência de Especialistas no Uso Racional de Medicamentos (URM), promovida pela OMS. Na ocasião foi requisitado um diálogo entre indústria farmacêutica, organizações representantes dos consumidores de medicamentos e o governo, a fim de melhorar o conhecimento e fluxo de informações sobre o tema ${ }^{13}$. A preocupação com os problemas de saúde causados pelo uso irrestrito de medicamentos, assim como a implantação de políticas que buscam restringir o consumo destas drogas e ampliar o acesso às informações necessárias, tanto pelos prescritores quanto pelos usuários, foram alguns dos temas tratados e regulamentados pela Conferência ${ }^{13}$. Embora os debates tenham se dado há 30 anos, o tema ainda tem gerado inúmeros conflitos e controvérsias.

A terminologia uso racional de medicamentos tem sido tratada como sinônimo do 'uso consciente'. Como exemplo, existem as recomendações de Lopes e Gricoleto ${ }^{13}$ a respeito do uso consciente de psicotrópicos, o qual deveria estar inserido em um processo de intermitente vigilância, com o intuito de garantir o fornecimento de informações e evitando possíveis falhas no processo compreendido desde a prescrição até a autoadministração da medicação. Os autores ainda citaram, como solução, a promoção do uso racional de 
medicamentos, deixando claro que tratam o termo "uso consciente" como sinônimo. Logo, percebe-se uma limitação na utilização da terminologia "uso consciente" de medicamento, restringindo o aprofundamento das concepções e atrasando as intervenções. Considerando que a palavra consciente preconiza possuir conhecimento e compreensão dos fatos, permitindo a capacidade de pensar profundamente sobre algo, espera-se que o indivíduo tenha autonomia para analisar criticamente todos os processos envolvidos na tomada de decisão relativa ao uso de medicamentos ${ }^{15}$.

A sociedade contemporânea tem paulatinamente se tornado mais consumista, fato que, segundo Bauman ${ }^{16}$, impacta a capacidade deliberativa do indivíduo, que passa a atribuir outras representações ao consumo além da que se refere à saciedade de necessidades materiais. A vulnerabilidade do consumidor diante do mercado econômico é reconhecida pela legislação brasileira, que possui uma eficiente regulamentação protetiva ${ }^{17}$. Dessa forma, preza-se o atendimento às necessidades dos consumidores, $o$ respeito à sua dignidade, saúde e segurança, com fins a prover melhoria da qualidade de vida. Ainda assim, têm-se investido na educação dos consumidores para o consumo consciente, destacando a sustentabilidade e os impactos negativos que o consumismo desenfreado pode causar ao meio ambiente, a origem do produto e a forma com que os produtores tratam o descarte de seus resíduos. Entretanto, pesquisa realizada pelo Ministério do Meio Ambiente aponta que apenas um terço dos brasileiros conhece o termo consumo consciente e, destes, somente $54 \%$ o definem corretamente ${ }^{18}$.

A transposição do consumo consciente para a relação com os medicamentos representa um potencial aliado na promoção da saúde global, pelo fato de muitos cidadãos não possuírem acesso às informações idôneas e integras. Acresce-se o fato de se encontrarem vulneráveis às imposições norteadas pelos interesses econômicos e a debilidade de sua enfermidade. Assim, a pergunta norteadora do estudo que fundamenta este artigo reside na questão de como tem sido aplicada a terminologia 'uso consciente de medicamentos' no contexto acadêmico e popular, tendo como hipóteses: a) o termo 'uso racional' não supre a expectativa de sinonímia do 'uso consciente' por não transpor aspectos práticos vinculados a custo e quantidade correta de medicamento, logo não considerando características sociais, individuais, ambientais e de comunicação; b) há diferenças na aplicação dos termos no meio científico e no meio popular; c) grupos ativistas que perpetuam estilos de vida saudáveis delegam igualmente a favor do autocuidado sustentável e consciente. Desta forma, o objetivo do presente estudo é analisar as terminologias 'uso racional' e 'uso consciente de medicamentos' de medicamentos, demonstrando como a temática vem sendo abordada, por meio de revisão integrativa quantitativa do conteúdo recuperado em textos científicos e na mídia digital. Os resultados foram discutidos detendo como ideia central a apropriação da terminologia, procurando identificar argumentos e valores dos agentes morais e, por meio da intermediação do diálogo, promover intervenções efetivas a fim de mitigar as vulnerabilidades permeando a reflexão e a discussão nos eixos saúde, cultura e ambiente.

\section{Métodos}

\section{Concepção acadêmica das terminologias 'uso racional' e 'uso consciente' de medicamentos}

A concepção acadêmica foi acessada por meio da categorização das informações disponíveis em artigos científicos recuperados através das bases de dados disponíveis no Portal de Periódico da Capes, aplicando os descritores 'uso consciente de medicamentos' e 'uso racional de medicamentos'. A recuperação de textos científicos decorrentes da aplicação dos descritores em português teve o intuito de limitar o universo amostral nas veiculações nacionais e de considerar a acessibilidade do idioma. Enquanto a aplicação em inglês visou apenas a certificação da incorporação ou não do termo em abrangência global. O conteúdo de 124 textos, de 1998 até 2015, recuperados foi categorizado nos contextos da saúde, cultura e ambiente, 
conforme a técnica de análise semântica de conteúdo de Bardin ${ }^{19}$ de acordo com os parâmetros: a) local da pesquisa; b) origem da informação; c) temas abordados; d) definição dos termos; e) referência a custo, quantidade, descarte, automedicação, efeitos colaterais, origem e condutas éticas; f) discussão com base em aspectos pessoais, culturais, de saúde e estilo de vida.

\section{Concepção popular das terminologias 'uso racional' e 'uso consciente' de medicamentos}

Os mesmos descritores utilizados na concepção acadêmica foram aplicados no provedor de busca Google. com, em decorrência da sua popularidade nacional, cujo viés de direcionamento de pesquisa procurou-se minimizar ao destituir o uso da ferramenta do login e aumentar o tamanho da amostra, conforme o perfil do usuário atrelado à identificação do IP do dispositivo. Assim, foram recuperados os 100 primeiros registros, sendo o conteúdo categorizado segundo a análise semântica de Bardin ${ }^{19}$, de acordo com os parâmetros: a) tipo de informativo; b) origem da informação; c) funções gerais e específicas; d) público); e) definição do termo; f) problemas identificados; $g$ ) soluções propostas; $h$ ) indicação de parâmetros éticos; $h$ ) acessibilidade da linguagem. Com o intuito de avaliar a abrangência do uso das terminologias foi acrescida à pesquisa em redes sociais Facebook e Youtube a mesma metodologia descrita, incluindo o registro do número médio de membros e de visualizações.

A caracterização do uso das terminologias, por grupos reconhecidos pela prática do consumo consciente, se deu pela aplicação do mesmo método descrito acima, sendo acrescentada a palavra 'ativismo'. Os 90 conteúdos selecionados em associação com a temática pretendida foram categorizados de acordo com a análise semântica de Bardin ${ }^{19}$ conforme os parâmetros: a) origem da informação; b) objetivos das postagens; c) temas abordados; d) número médio de visualizações.

\section{Procedimentos estatísticos e legais}

A categorização dos parâmetros foi transcrita para uma planilha eletrônica, em que as categorias foram reorganizadas tematicamente com base na classificação dos elementos, segundo suas discrepâncias e semelhanças, e reagrupadas para realização da análise quantitativa. A homogeneidade da frequência das variáveis resultantes de cada categoria analisada foi testada através do teste não paramétrico qui-quadrado, considerando como hipótese nula a uniformidade da amostra com um nível de significância de 95\% e um erro de $5 \%$. Para atender aos princípios éticos, o estudo foi realizado em conformidade com a Declaração de Helsinque e as resoluções CNS 466/12 e 510/2016 respeitando a integridade e o anonimato dos internautas, bem como o tratamento, a análise e a preservação dos dados.

\section{Resultados}

\section{Concepção acadêmica das terminologias 'uso racional' e 'uso consciente' de medicamentos}

Nos textos científicos recuperados não foi identificada a aplicação da terminologia 'uso consciente' de medicamentos. A categorização referente ao 'uso racional' evidenciou a sua apropriação pelo meio acadêmico nacional, principalmente nos períodos entre 2010-2015 (52,4\%), 2004-2009 (38,7\%) e 1998$2003(8,9 \%)\left(X_{(2)}^{2}=36 ; \mathrm{P}<0,001\right)$, e foi relacionada com a informação técnica (Figura 1). Ressalva-se que a utilização dos termos em inglês retornou 268 resultados para uso racional e um para uso consciente, sendo este relativo a uma citação. Os textos analisados tiveram como foco a sensibilização e o efeito do medicamento em detrimento de informações globais. A maioria significativa não se referiu a características pessoais, aspectos culturais e da saúde, estilo de vida, custo adequado da medicação, quantidade necessária para cumprir o tratamento, automedicação, descarte apropriado, origem da medicação ou vínculo com 
questões éticas. Na maioria dos textos (92,8\%) não foi possível identificar correntes ou princípios éticos, sendo que das identificadas prevaleceu a abordagem antropocêntrica e princípios utilitaristas (22\%), nãomaleficência (33\%), beneficência (33\%) e equidade (11\%).

\section{"Uso Racional" de medicamentos na Perspectiva acadêmica}

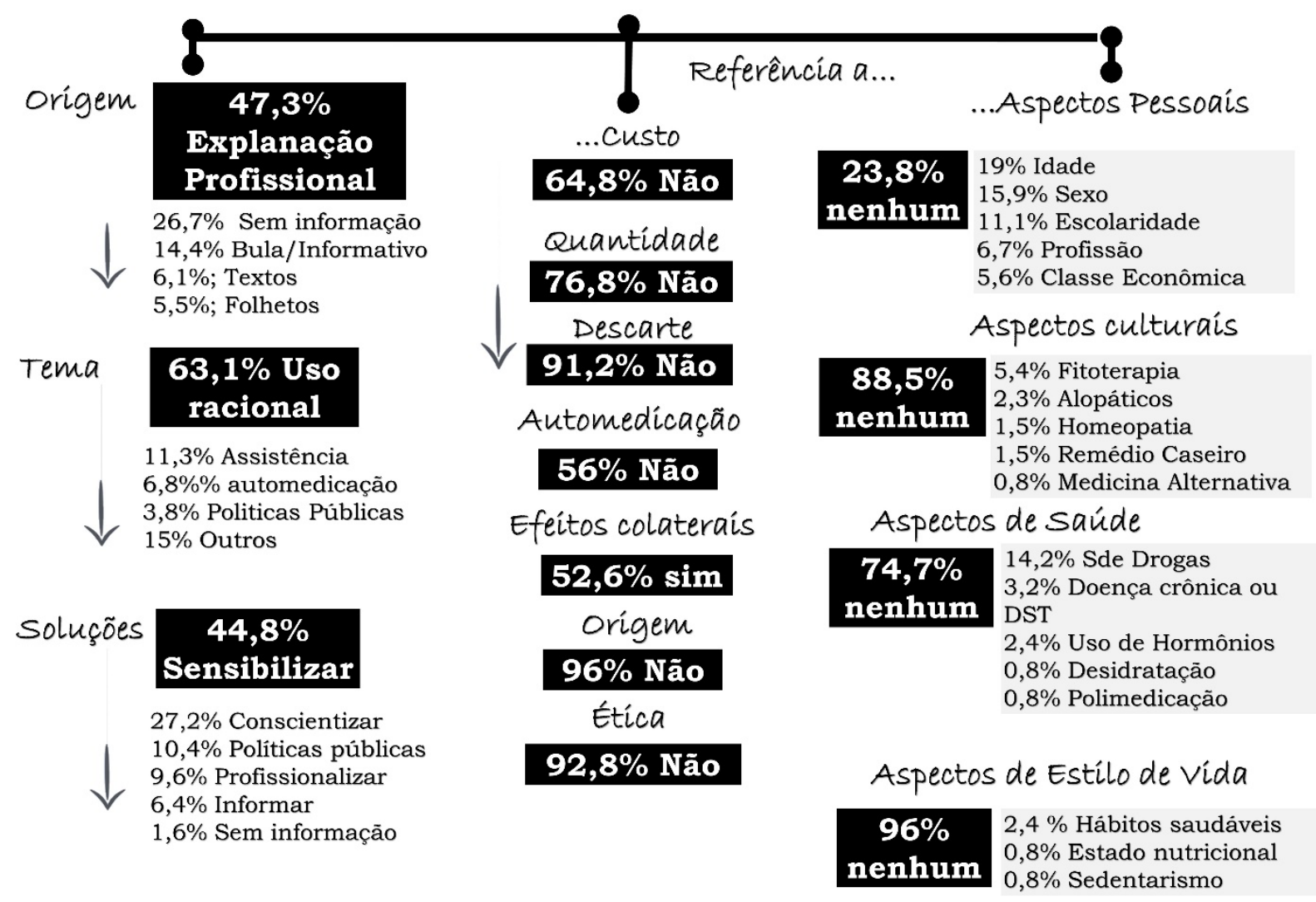

Figura 1 - Representação da categorização dos textos científicos contemplantes da terminologia 'uso racional de medicamentos' ${ }^{\text { }}$. Fonte: As autoras (2019).

\section{Concepção popular das terminologias 'uso racional' e 'uso consciente' de medicamentos}

$\mathrm{Na}$ abordagem, predominaram sites de notícias de origem privada, que tratavam principalmente do uso racional dos medicamentos, com função de informar à sociedade em geral. Os termos 'uso racional' e 'uso consciente' de medicamentos foram aplicados, sendo o 'uso consciente', contrariamente ao 'uso racional', atrelado à sociedade e não aos profissionais. Foi identificada linguagem e direcionamento popular, mas com pouco uso de recursos de imagens. Igualmente ocorreu em baixa frequência a proposta de soluções, assim como os problemas identificados com a prática do uso irracional e inconsciente de medicamentos (Figura 2).

Os dados obtidos a partir da pesquisa nas redes sociais (Figura 2) evidenciaram predomínio do tema automedicação, enquanto no Youtube prevaleceu o 'uso racional de medicamentos', assim como problemas identificados pela prática do uso irracional de medicamentos atrelados à intoxicação, dependência e efeitos colaterais.

A homogeneidade das categorias de cada parâmetro analisado foi testada por meio do teste qui-quadrado, sendo os valores significativos $(P<0,05)$ representados com destaque nos quadros de fundo negro. 
Na análise da concepção popular condicionada aos ativistas, o conteúdo tratava predominantemente de notícias ( $80 \%)\left(X_{(7)}^{2}=333 ; \mathrm{P}<0,001\right)$, das quais excluindo as que não abordavam diretamente o tema (52,3\%), a maioria se posicionava contra o uso de animais em pesquisa (49\%) e sobre o acesso a medicamentos e o direito à saúde (32\%) $\left(X_{(7)}^{2}=196 ; \mathrm{P}<0,001\right)$, sendo registrada também a liberação da canabis pela Anvisa (7\%) e o aumento da fiscalização, por esse órgão, contra exposição de agentes nocivos à saúde $(2,3 \%)$ e críticas à indústria farmacêutica além de protesto contra homeopatia ( $2,3 \%$ cada). Os temas envolviam: protetores de animais (28,9\%), direitos humanos (24,4\%), ativismo em geral (12,2\%), ambientalistas (7,8\%), ativismo judicial (6,7\%), ativistas políticos (6,7\%), outros (LGTB, feminismo, pacifismo, sindicalismo e veganismo) $(13,3 \%)$ contando com a visualização média de 1847,5 \pm 4633 (60;6-32740).

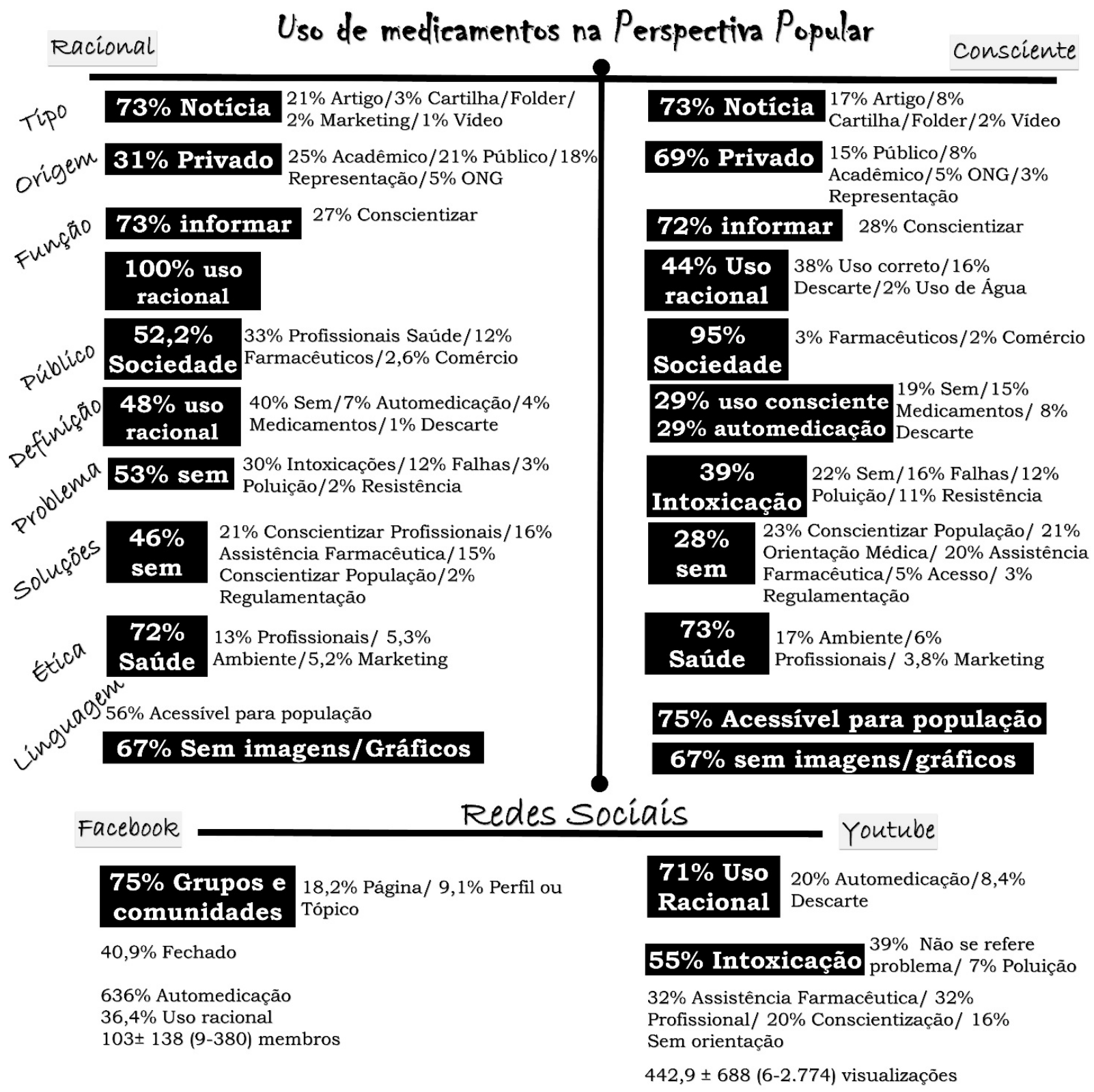

Figura 2 - Representação da categorização do conteúdo digital popular sobre o 'uso racional' e 'uso consciente' de medicamentosii. *A homogeneidade das categorias de cada parâmetro analisado foi testada por meio do teste qui-quadrado, sendo os valores significativos $(P<0,05)$ representados com destaca que nos quadros de fundo negro.

Fonte: As autoras (2019). 


\section{Discussão}

Os dados do estudo em questão possibilitaram o mapeamento da utilização da terminologia 'uso racional' de medicamentos e a incompatibilidade de sinonimizá-la com a terminologia 'uso consciente' de medicamentos. Assim como permitiram subsidiar intervenções no consumo de medicamentos e, consequentemente, obter melhoria da qualidade de vida e ambiental.

No meio acadêmico foi atestada a exclusividade do emprego da terminologia 'uso racional' e a incompatibilidade de sua incorporação na abrangência do termo 'uso consciente', tal como concebido no presente estudo. A utilização do termo 'uso racional' não contemplou a amplitude dos parâmetros indicadores de saúde global, uma vez que estes demandam a inserção das dimensões econômicas, sociais, psicológicas, ambientais, de comunicação e de valores éticos na decisão de como usufruir dos medicamentos. Contrariamente, demonstrou um viés técnico, de acessibilidade e segurança do medicamento, cuja comunicação foi prioritariamente estabelecida entre a academia e os profissionais da saúde. Assim, consequentemente inábil em invocar a conduta do cidadão que demanda instrumentalização para um consumo consciente e sustentável. Segundo Schenkel e colaboradores ${ }^{20}$, a incorporação dos princípios do uso racional foi um ganho para assistência farmacêutica diante de um cenário nacional em que 70 milhões de brasileiros não têm acesso ao medicamento e os que têm necessitam despender quase metade do seu salário na sua aquisição. Mota e colaboradore ${ }^{21}$ e Aquino ${ }^{22}$ alertaram para existência de requisitos para $o$ URM ser implementado, os quais envolvem variáveis como a apropriação de conhecimentos e mudança de conduta de agentes morais representados pelos profissionais da saúde, legisladores, indústria, comércio, governo e pacientes, reafirmando a necessidade do debate multidisciplinar.

No meio científico, o foco na sensibilização do cidadão para o URM e os efeitos nocivos do uso irracional sobrepôs as informações globais, que levam em consideração características individuais e culturais dos usuários de medicamentos. Essa informação confirma a percepção de Soares e Camargo-Junior ${ }^{23}$ e de Backes e colaboradores ${ }^{24}$, que afirmaram que a subjetividade na área médica foi substituída pela objetividade, acabando por negligenciar certas características socioculturais e o respeito aos valores, presentes também no processo terapêutico. A padronização de regras e normas tenderam a afastar paulatinamente os médicos de seus pacientes. A forma como o URM vem sendo conduzido até então não contempla as consequências do desenvolvimento biotecnológico e das mudanças no estilo de vida, principalmente em grandes centros urbanos. Assim como os preocupantes impactos ambientais e sociais geradores de agravos à saúde demandam uma compreensão mais ampla da relação com a medicamentação.

A mútua relação entre a saúde e o meio ambiente já é reconhecida pela saúde pública, que instituiu a saúde ambiental como uma estratégia de desenvolvimento sustentável visando à promoção de qualidade de vida e saúde e superando os impactos da urbanização, da industrialização e da iniquidade social ${ }^{25}$. Augusto $^{26}$ propôs um novo modelo de vigilância à saúde com foco na prevenção por meio da vigilância em saúde ambiental como um campo da saúde coletiva. Para o autor, é fundamental compreender o processo de saúde/doença atrelado a elementos sociais, ambientais, de sustentabilidade, risco, contexto e interdisciplinaridade. No entanto, o sucesso das intervenções depende de um cidadão instrumentalizado para o autocuidado responsável e crítico, fruto da compreensão sobre influência que o ambiente físico, social e mental exerce em relação à saúde como promotora da prevenção, como atitude mitigatória da situação de vulnerabilidade às consequências da enfermidade e do próprio processo de remediação da doença.

A impossibilidade de sinonímia entre as terminologias 'uso racional' e 'uso consciente' atestadas no contexto científico e popular corrobora a necessidade de implementação de uma terminologia mais ampla, importante para aprumar os diagnósticos e as intervenções. Segundo Marini ${ }^{27}$, o desenvolvimento de produtos terminológicos nas esferas governamentais, acadêmicas ou privadas possibilitam ganho de qualidade na comunicação entre os profissionais institucionalizados. Machado e outros ${ }^{28}$ associaram o uso da 
terminologia como instrumento de atuação do profissional da área da saúde coletiva, uma vez que direciona a avaliação e a intervenção da determinação social do processo saúde/doença. A partir da concepção da terminologia, a sua consolidação passa a configurar como elemento simplificador da comunicação, uma vez que traz atrelada uma série de conceitos e condutas. Na questão específica da saúde e do uso consciente do medicamento, Schenkel e colaboradores ${ }^{20}$ ressaltaram que há assimetria nas informações, destacando que as mesmas não possibilitam que os consumidores finais atuem como agentes morais na decisão do que devem consumir. Uma vez que são omitidos dados sobre a qualidade, segurança, eficácia e características especificas do medicamento, são nitidamente identificados interesses contrapostos. Assim, espera-se que, ao instituir a concepção do uso consciente de medicamentos, o consumidor, o paciente, os profissionais da saúde, a academia e o mercado econômico trabalhem em sinergia no intuito de promoção de saúde tanto na remediação quanto na prevenção de doenças.

Embora a dimensão econômica do usuário de medicamentos esteja inserida no conceito de 'uso racional', demanda-se um consumidor consciente, uma vez que a aquisição excessiva de medicamentos pode ser influenciada por questões que extrapolam a recuperação da saúde. Estas podem ser influenciadas por apelos comerciais ou emocionais, advindas das consequências da exploração dos recursos naturais e dos excedentes da produção. A concepção de consumo consciente extrapola a questão dos medicamentos e visa suprir uma reivindicação contemporânea e, assim, diminuir a vulnerabilidade do consumidor diante do mercado capitalista. Para Silva e outros ${ }^{29}$ é necessário estabelecer uma conexão entre consumidores e organizações econômicas em prol de uma sinergia promotora de mudanças mútuas de paradigmas quanto ao consumo e a relação com a natureza. A forma de consumo exige uma intervenção multidisciplinar que considere sua flexibilidade, associação com o momento histórico e político e deve estar alicerçada em uma característica intrínseca do ser humano de saciar suas necessidades, preferências e desejos. Contudo, o desenvolvimento tecnológico e a instauração das sociedades capitalistas conduziram à compreensão da insustentabilidade do sistema de produção e consumo atual, causando a contínua e catastrófica degradação dos recursos naturais e dos seres vivos do planeta. Além disso, levou a consequências até então insuficientemente compreendidas no contexto social, cultural e político.

Desde 1992, com a Conferência das Nações Unidas sobre o Meio Ambiente e o Desenvolvimento, o consumo sustentável compõe a Agenda $21^{29}$. O documento atribui, ao consumo, a falta de consciência das desigualdades econômicas, sociais, raciais, de gênero, a exploração do trabalho, a democratização das decisões, a finitude dos recursos naturais, o aumento dos resíduos, a emissão de poluentes, a ameaça à biodiversidade e as mudanças climáticas. Conclama, assim, à realização de mudanças no padrão de consumo de modo a condicionar os impactos, à responsabilidade ética para com as pessoas e o ambiente, ao apoio do comércio justo e à participação em campanhas em defesa dos direitos humanos e do meio ambiente. Repensando o consumo desta forma, propõe a reciclagem, o descarte consciente, a preocupação com a origem do produto, o voluntariado, o apoio ao comércio local e a preferência por produtos ecológicos, naturais, orgânicos e com pouca embalagem.

O uso consciente do medicamento deve prever uma dimensão social, que no presente estudo não foi identificada nos conteúdos com abordagem do URM, contudo, indica apropriação pelo "uso consciente" ao direcionar a informação para sociedade, visar à conscientização da população e à acessibilidade da linguagem. Lefèvre $^{30}$ indicou uma associação entre sociedades imaturas e a concepção reducionista da doença a um fato orgânico, destituída de influências sociais e comportamentais, e legitimação da remediação na ciência. Consequentemente, o medicamento passou a simbolizar saúde, levando o usuário a não se perceber como doente pelo fato de estar consumindo um remédio.

Essa concepção resulta na simbologia do medicamento como um bem de consumo que reduz a distância entre o desejo e a promoção de saúde. Assim, demanda um esforço menor do que o necessário para promover mudanças de hábitos e condutas. Para o autor ${ }^{30}$, a exploração mercantil da saúde/doença constitui um grave 
problema de saúde pública, pois ilude e funciona como paliativo de sofrimento de milhares de pessoas que perpetuam o mito de que o medicamente finda a dor. Portanto, atribui a responsabilidade aos profissionais da saúde na promoção de práticas educativas em prol do amadurecimento das sociedades e inserção do real papel do medicamento na concepção popular. Luz ${ }^{31}$ interpretou na dimensão macrossociológica das representações sociais desde as proeminentes medicinas alternativas até as práticas biomédicas, associadas à crise sanitária e à crise médica na relação com o paciente. Segundo o autor, a doença, balizada pelo paradigma científico e o saber médico, ocupou o lugar central que deveria ser do paciente ou grupos populacionais muitas vezes vulneráveis, suas relações biopsicossociais e ambientais e o exercício da arte de curar. Luz ${ }^{31}$ frisou a associação entre a crise da saúde e as desigualdades sociais, a inadequação de políticas e o fenômeno denominado pequena síndrome biopsiquica epidemiológica do mal-estar, consequência do estilo de vida contemporâneo, principalmente dos grandes centros urbanos, com elevada carga de estresse, baixa qualidade de sono, nutrição e atividades físicas. Somam-se a essas questões a transformação cultural promovida com a globalização e a consequente perda de valores milenares na esfera ética, política, relacional e sexual, privilegiando o individualismo, o consumismo e o status. Freitas-Santos e Marques ${ }^{32}$ alertaram que a conduta do paciente também passou por transformações nas últimas décadas, o que reivindica um ajuste de todo sistema circundante. Assim, o paciente transpôs de um elemento passivo e submisso às determinações médicas, das décadas de 1960 e 1970, ao paciente protegido pela bioética institucional e pela legislação a partir da década de 1980, conduzindo ao atual protagonista, corresponsável pelo tratamento, empoderado pelo acesso ao conhecimento, diálogo com médico e participação da família, resultando em condutas autorregulatórias.

O uso consciente do medicamento deve prever uma dimensão individual, uma vez que a representação da saúde e o autocuidado tem influência da idade, sexo, nível intelectual, identificados nos conteúdos URM, contudo associados aos riscos da automedicação e à segurança do medicamento quanto aos efeitos colaterais. O marketing se apropria dessas variáveis a fim direcionar a propaganda para grupos específicos e induzir a adesão a determinados medicamentos. Huertas e Campomar ${ }^{33}$ realizaram uma avaliação de consumidores diante de propaganda de remédios para emagrecer e atestaram, comparando com resultados de outras pesquisas, que o consumidor brasileiro tem uma atitude cognitiva quanto ao produto anunciado, empregando intenções racionais na decisão de consumi-lo. Assim, constaram que o uso de intervenções emocionais pode influenciar negativamente os consumidores. Embora o uso informação racional seja a preferida no quesito medicamentos, os autores alertaram que também pode imputar efeitos negativos ao promulgar que o conhecimento pode conduzi-lo a pressionar o médico para que receite um medicamento específico ou optar pela automedicação.

O autocuidado é esperado como uma conduta ética e respeitosa consigo mesmo e com o outro e isso remete ao autoconhecimento e ao envolvimento com todos os processos inseridos na aquisição, remediação e prevenção de agravos à saúde. Mendonça e Menandro ${ }^{34}$ realizaram um estudo com graduandos da área da saúde e constataram que, embora esses futuros profissionais já estejam habilitados a intermediarem o processo saúde/doença, uma deficiência quanto ao autocuidado foi apresentada. Os respondentes associaram o cuidado com a busca de serviços de saúde em uma situação de adoecimento e quando este passa a interferir nas atividades sociais, sendo muitas vezes praticada a automedicação apoiada nos conhecimentos técnicos. Os graduandos tenderam a reduzir a doença à dimensão biológica e não demostraram praticar a prevenção e o cuidado integral. Para os autores esse resultado é preocupante, pois poderá comprometer a empatia com o paciente e a promoção de hábitos de vida saudáveis e a prevenção de doenças.

O uso consciente do medicamento deve prever uma dimensão ambiental dos impactos da produção, distribuição e descarte dos medicamentos. Contudo, embora essa dimensão ainda seja subabordada em ambas aplicações das terminologias, foi mais pronunciada como referência ao uso consciente, porém, associada ao risco de intoxicação. A preocupação com o uso de recursos naturais, o uso de animais para 
validação dos medicamentos e as catastróficas consequências ambientais decorrentes do descarte de excedentes de medicamentos metabolizados ou não, começam a configurar como uma exigência que todo consumidor consciente deve considerar. Carvalho e outros ${ }^{35}$ denominaram os resíduos de medicamentos de "substâncias emergentes" com elevado potencial de risco ambiental, mesmo em baixas concentrações. Os interferentes endócrinos do metabolismo de inúmeros organismos têm alertado a comunidade cientifica. Para os autores, o passivo ambiental gerado com o sistema de pesquisa, produção, distribuição e descarte de medicamentos demandam a percepção e o comprometimento dos usuários, através da promoção de campanhas, embalagens fracionadas e doação de excedentes para programas de farmácia solidária. Embora já seja aceitável no meio científico e popular que a maioria das doenças biopsiquicas modernas são consequências da transformação promovida na natureza pela intervenção humana ${ }^{31}$, a facilidade de acesso e o incentivo da mídia geram consumo excessivo de medicamentos. Consequentemente, acarretam um problema de saúde pública, tanto relativo à administração de sobras quando ao descarte inadequado. Segundo Alvarenga e Nicoletti ${ }^{36}$, o Brasil é considerado um dos maiores consumidores mundiais de medicamentos e recolhe cerca de $\mathrm{R} \$ 30,2$ bilhões, resultando em maior quantidade de embalagens e sobras de medicamentos descartadas incorretamente. Os autores destacaram, ainda, os resíduos produzidos por serviços de saúde (animal e humana), drogarias, farmácias de manipulação, distribuidores de produtos farmacêuticos e indústria farmacêutica e a responsabilidade dessas instituições no recolhimento e devolução de medicamentos. Assim como no descarte de medicamentos rejeitados pelo controle de qualidade e todas as perdas envolvidas no processo.

O descarte incorreto de medicamento não é o único vilão do impacto ambiental. Estudo publicado por Melo e colaboradores ${ }^{37}$, realizado em efluentes de estações de tratamento de esgoto, demonstraram que a maior parte dos resíduos químicos encontrados são provenientes da excreção metabólica de fármacos utilizados por seres humanos e demais animais. Nunes ${ }^{38}$ destacou que as estações de tratamento de águas residuais não são eficazes para esses tipos de moléculas, o que faz com que estas substâncias passem quase inalteradas através destes dispositivos e, desta forma, são capazes de afetar animais, plantas e o solo, alterando sua funcionalidade. Ainda assim, pesquisas realizadas com cidadãos como os moradores do interior de São Paulo entrevistados por Carmo e outros ${ }^{39}$, têm elucidado que, apesar de reconhecerem que praticam o descarte inadequado, argumentam que desconhecem os procedimentos corretos, demandando intervenções mais efetivas.

O uso consciente do medicamento deve prever uma dimensão de comunicação com potencial de interferência na relação estabelecida entre a academia, órgãos gestores e a população por meio da geração e propagação de conteúdo e conhecimento. A utilização do termo 'uso consciente' pela mídia digital legitima a sua apropriação pela bioética e comprova a hipótese de sua abrangência nas dimensões, geográficas, temporais, ecossistêmicas, físicas, mentais e espirituais. Estas, podem ser inseridas na formação do cidadão que busca exercer o autocuidado como princípio biológico e ético, ao administrar os medicamentos com responsabilidade, precaução e cuidado. Camargo-Borges e Japur ${ }^{40}$ referiram-se aos novos discursos democráticos no contexto do Sistema Único de Saúde (SUS) que consideraram como prática humanizada a dissociação da saúde meramente como técnica, mas associada à construção de uma relação de corresponsabilidade, favorecendo a todos os envolvidos no processo. Os autores trabalharam o autocuidado inserindo-o na perspectiva construtivista social cuja atenção em saúde deve ser compreendida no contexto histórico e cultural, considerando que os sentidos são dinâmicos e dependem das interações entre profissionais e comunidade.

A pesquisa aqui apresentada atestou a apropriação pela mídia digital com confluências no emprego das terminologias, contudo indicando: ampliação da abrangência do 'uso consciente' com pronunciamento do interesse não só do setor público como do acadêmico; associação ao uso racional, o uso correto e o descarte; estabelecendo comunicação predominantemente com a sociedade, com adaptação da linguagem; incluindo 
nos debates a automedicação, o risco de intoxicação, a conscientização da população, orientação médica e assistência farmacêutica como principais soluções; uma ética ambiental associada com uma ética para saúde. Por outro lado, o interesse popular na busca de informações ainda não foi tão pronunciado, como se pode observar na média de visualizações de vídeos sobre o tema, possivelmente por ainda estar atrelado ao uso racional e ao direcionamento profissional. Nunes ${ }^{41}$ considerou as novas mídias como um espaço democrático promotor da expansão da informação e potencial influenciador na tomada de decisão de autoridades e exercício da cidadania individual e coletiva, uma vez que promovem a circulação de informações ultrapassando limites temporais, geográficos e geracionais, debates, manifestações, geração de conteúdo e opinião. Segundo o autor, os cidadãos com acesso a informações se habilitam a atuar politicamente e democraticamente na sociedade a partir da articulação eficaz de seus desejos e ideias e decisões. Assim, as novas mídias promovem novas relações na configuração entre ciência/sociedade/tecnologia. Freitas-Santos e Marques ${ }^{32}$ propuseram o uso da internet para educação do paciente como parte do programa de educação terapêutica. Segundo os autores, o acesso monitorado do paciente pode melhorar seu conhecimento, habilidades e potencial de influenciar as suas condutas necessárias para manter ou melhorar a saúde e, consequentemente, a comunicação e a relação com o profissional da saúde. Os autores acreditam que essa ferramenta pode contribuir para solucionar questões éticas, políticas e econômicas, conciliando demandas do paciente com as limitações do sistema de saúde; porém, isso demanda planejamento, monitoramento e avaliações constantes. Segundo Cabral e Trevisol ${ }^{42}$, a maioria dos médicos, entrevistados em sua pesquisa, acredita que o paciente que acessa a internet e detém as informações exige um tempo maior de consulta, sendo que mais da metade deles acredita que as informações são importantes para o conhecimento da doença e a adesão ao tratamento e estimula o médico a se atualizar. Contudo, ressaltaram o perigo de os pacientes acreditarem em qualquer informação sem senso crítico ou pré-requisitos tecnoculturais para acessá-las, correndo risco de adquirem medicamentos proibidos ou falsos com promessas de curas milagrosas ou antiéticas.

Sobre esta questão, há dados alarmantes publicados por Aquino ${ }^{22}$ sobre o uso de medicamentos no Brasil revelando que aproximadamente $1 / 3$ das internações ocorrem devido ao uso incorreto de fármacos; além disso, este mesmo motivo também é o responsável por $27 \%$ das intoxicações e $16 \%$ das mortes. Souza e outros ${ }^{43}$ alertaram para a necessidade de intensificação de campanhas populares mais abrangentes que contemplem os perigos do uso errôneo de medicamentos. Da mesma forma que Silva e colaboradores ${ }^{44}$, assim como Araújo e Silva ${ }^{45}$, reforçaram a importância da informação e comunicação em saúde, as quais permitem avanços significativos para estabelecer novos paradigmas que auxiliem no desenvolvimento de programas que contribuam para melhoria da qualidade de vida da população, independentemente de sua classe econômica.

A iniciativa individual na geração de debate sobre o uso consciente de medicamentos ainda é incipiente, mas já indica interesse na reflexão sobre os impactos da automedicação. Embora o conteúdo digital associado ao ativismo tenha conseguido grande quantidade de visualizações, ele não trazia de fato um posicionamento diretamente relacionado ao consumo consciente de medicamento. Contrariando o esperado, principalmente do movimento vegano que prega uma nutrição mais natural, corroborando com uma posição contrária ao uso de animais em experimentação $4^{6}$. Para Loures ${ }^{47}$, todo cidadão possui o direito constitucional ao meio ambiente saudável e informações ambientais, a fim de, por meio do envolvimento do cidadão, individual ou coletivamente, materializar os anseios e especificidades biopsicossociais e, assim, legitimar as decisões públicas. Para a autora, a instrumentalização para o exercício do princípio da participação popular por meio do acesso à informação ambiental é "assegurado pelo sistema jurídico instituído com a Constituição Federal de $1988^{\prime \prime 4}$ e por tratados internacionais. O objetivo é que o cidadão esteja ciente da importância de sua participação concreta e efetiva nas políticas públicas e de suas responsabilidades com relação aos bens e valores ambientais, Inclusive de não se omitir diante de condutas sociais contrárias a essa expectativa. 
Dessa forma, o direito deixa potencialmente de ser instrumentalizado para dominação, permitindo a reflexão das relações e os conflitos decorrentes do desenvolvimento tecnológico, cuja informação deve auxiliar a identificação e remediação dos problemas. Borelli e outros ${ }^{48}$ identificaram dois tipos de consumidores conscientes: o individualista e calculista, que visa em primeiro lugar ao controle financeiro; e o coletivista ecológico que almeja compreender as questões ambientais e sociais decorrentes de suas decisões de consumo e muda suas condutas em prol de um ambiente melhor para todos. Os autores frisaram que este último é o almejado socialmente e demanda informação acessível, compreensível e atraente e plausível de reverter em sensibilização, conscientização e ação. Os autores estimularam a inserção da temática na educação básica formal e não formal a fim de quebrar as barreiras das argumentações sobre a dificuldade de alterar costumes e interferir nas relações sociais. Luz ${ }^{31}$ relacionou a inquietação social aos movimentos de contracultura, ao aumento de consciência ecológica, pronunciada nas últimas décadas, e à mudança do paradigma de saúde que passou a associar a medicina tecnológica como antinatural e antiecológica, salientando que a adesão à medicina naturalística se deu, inicialmente, pelo público jovem e dotado de mais recursos financeiros e intelectuais. Posteriormente, a inclusão das camadas populares mais carentes desses recursos, que retomam padrões tradicionais de $\mathrm{cura}^{4}$, como a medicina tradicional chinesa representada principalmente pela acupuntura, ayuvédica e homeopatia. Essas inovações que, na verdade, constituem uma retomada, foram prontamente apropriadas pela mídia que reconheceu o interesse popular, e paulatinamente vêm conseguindo legitimação institucional, sendo incorporadas até mesmo por instituições públicas.

As experiências sociais associadas a grupos contrários e ONGs impulsionam a participação democrática na gestão dos governos que almejam o respeito ao paciente como cidadão e sua autonomia e a cobrança por serviços públicos de saúde pública com medicina alternativa. Segundo Fischer e outros ${ }^{4}$, a pressão dos movimentos sociais e da mídia pela recuperação da relação médico/paciente confronta com os incrédulos sistemas institucionais acadêmicos e com o mercado da cura em busca do encontro da cultura das medicinas tradicionais e as novas representações de saúde/adoecimento/cura/natureza/prevenção.

Os conteúdos analisados apresentaram baixa referência a condutas éticas, sendo que, nos poucos casos em que foi possível identificar um discurso ético, foram identificados os seguintes princípios éticos: a) antropocêntrico/utilitarista, conclamando tratamentos medicamentosos que ofereçam o máximo benefício com o mínimo de riscos ao paciente e ao meio em que o mesmo está inserido; b) a não-maleficência, sugerindo o estabelecimento de critérios para promoção e propagandas de medicamentos; c) a beneficência, procurando garantir o direito à saúde e dignidade humana; d) a equidade, apontando critérios que possibilitem que toda população possua qualidade de vida. É inegável a relevância de fundamentar a reflexão da temática com princípios éticos, pois desta forma é possível balizar os debates em busca de atender interesses e valores comuns, e assim atingir um novo modelo de ética no campo da assistência à saúde e à pesquisa. Essas ideias são corroboradas por Carneiro e outros ${ }^{49}$ e também por Backes e outros ${ }^{24}$, ao ressaltarem a necessidade de se extrapolar a deontologia que normatiza o exercício das profissões vinculadas à saúde, de forma que as práticas de cuidado e o autocuidado multiculturais presentes em uma sociedade sejam considerados alterações necessárias na relação médico-paciente.

Os resultados do presente estudo identificam o cidadão como vulnerável diante de interesses econômicos que o reduz a um objeto, destituindo o valor mais precioso de qualquer ser vivo, que é a sua saúde. Desta forma, como Chauhan e outros ${ }^{50}$, demandamos a transposição das responsabilidades envolvidas nos processos de pesquisa, produção, administração e descarte dos medicamentos, e defendemos que seja dada uma atenção especial aos processos de comunicação estabelecidos entre as instâncias produtoras, distribuidoras, regulatórias e os consumidores finais. Luz ${ }^{31}$ ressaltou a importância da educação médica e formação de recursos humanos que ultrapassem o sistema instaurado de objetificação dos pacientes e mercantilização das relações médico/paciente e de uma concepção do paciente como consumidor de 
bens médicos. Por sua vez, Jha e colaboradores ${ }^{51}$ sugeriram que a educação das pessoas deve envolver múltiplos materiais como folhetos, programas radiofônicos e televisivos, além da educação contínua dos profissionais da saúde. Desta forma, retoma-se a singularidade do paciente e do princípio do cuidado, precaução e responsabilidade. Huertas e Campomar ${ }^{33}$ alertaram para a educação do consumidor de modo que o mesmo seja capaz de compreender, interpretar e superar as dificuldades na aplicação idônea e esteja consciente das informações obtidas sobre medicamentos. Segundo Freitas-Santos e Marques ${ }^{32}$, ao incluir a educação como parte do tratamento, os aspectos pessoais e emocionais conduzem à centralização da pessoa e não da doença, de modo que o paciente acumule informações e desenvolva competências e habilidades para o autoconhecimento e para realizar escolhas conscientes sobre o autocuidado, o gerenciamento do seu tratamento e sobre a sua saúde e qualidade de vida mesmo na ausência de enfermidades. Além de protagonizar a geração e propagação de conteúdos e auxiliar outras pessoas na mesma situação. Os autores propuseram que os profissionais monitorem e orientem as pesquisas certificando-se que o paciente seja hábil para selecionar informações de qualidade, ressaltando que já existem instrumentos e protocolos internacionais e nacionais que visam à qualificação de sites com informação sobre saúde. Caso o paciente não esteja instrumentalizado no acesso à informação, poderá se colocar em situação de vulnerabilidade tomando decisões comprometedoras balizadas por informações ilícitas, incompletas ou tendenciosas.

\section{Considerações finais}

Os resultados obtidos ilustram o panorama da utilização das terminologias 'uso racional' e 'uso consciente' de medicamentos pelo meio científico e popular brasileiro, sustentando a proposta da presente pesquisa de ampliação da abrangência da terminologia, de modo a incluir elementos subsidiários com vistas à promoção da saúde global. A implementação e consolidação da terminologia 'uso consciente de medicamentos' é essencial para o direcionamento das políticas educacionais e de comunicação visando à instrumentalização do consumidor de medicamentos à prática do autocuidado e cuidado com o outro e com o ambiente. Demanda, para tal, a ressignificação do mecanismo saúde/doença e a consideração dos processos envolvidos na pesquisa, produção, distribuição e descarte de medicamentos assim como as consequências de suas decisões em qualquer uma destas etapas.

A instauração da terminologia 'uso consciente de medicamento' acrescenta a dimensão de saúde na concepção de consumo consciente e prevê intervenções na promoção do cidadão e paciente como agente moral, protagonista, crítico e consciente de suas decisões. Logo, requer o desenvolvimento de tecnologias de comunicação e educação que posicione o indivíduo no centro, ao invés de o foco ser o diagnóstico e a contenção de sua doença. O cidadão consciente, por outro lado, deve valorizar a sua saúde, e despender cuidados mesmo na ausência de enfermidades, primando por um ambiente físico, emocional, social e espiritual promotores de qualidade de vida própria e, consequentemente, impactando positivamente os demais seres vivos, desta e de futuras gerações, ao praticar um consumo consciente e sustentável.

\section{Referências}

1. Bittencourt PCT. Uso abusivo de medicamentos. [Internet]. [lugar desconhecido]; 2009 [citado em 2017 set. 18] Disponível em: https://goo.gl/6UkWhQ

2. Fortes PAC, Ribeiro H. Saúde global em tempos de globalização. Saúde Soc [Internet]. 2014 [citado em 2017 set. 18];23(2):366-75. Disponível em: https://goo.gl/TUyXWM

3. Fischer ML, Cunha T, Renk V, Sganzerla A, Zacarkin dos Santos, J. Da ética ambiental à bioética ambiental: antecedentes, trajetórias e perspectivas. Hist Ci Saúde-Manguinhos [Internet]. 2017;24(2):391-409. doi: https://doi.org/10.1590/S0104-12902014000200002

4. Fischer ML, Palodeto MF, Santos, E. Uso de animais como zooterápicos: uma questão bioética. Hist Ci Saúde-Manguinhos.2018;25(1):217-243. doi: http://dx.doi.org/10.1590/S0104-59702018000100013 
5. Vieira A, Rosa C, Waskow G, Scheuer T, Coser JA. A abordagem da bioética na formação do profissional de biomedicina, farmácia e ciências biológicas. In: Anais do 15 Seminário Interinstitucional de Pesquisa e Extensão; 13 Mostra de Iniciação Científica; 8 Mostra de Extensão. 2010; Cruz Alta. Cruz Alta: UNICRUZ; 2010.

6. Potter VR. Bioética: ponte para o futuro. São Paulo: Edições Loyola; 2016.

7. Levai LF. Crueldade consentida: crítica à razão antropocêntrica. R Dir Animal. 2006;1(1);172-90. doi: http://dx.doi.org/10.9771/rbda.v1i1.10246

8. Garrafa V, Porto D. Bioética, poder e injustiça: por uma ética de intervenção. In: Garrafa V, Pessini $L$, organizadores. Bioética, poder e injustiça. São Paulo: Loyola; Sociedade Brasileira de Bioética; 2003. p. 103-14.

9. Fagundes MJD, Soares MGA, Diniz NM, Pires JR, Garrafa V. Análise bioética da propaganda e publicidade de medicamentos. Ci Saúde Coletiva. 2007;12(1):221-29. doi: http://dx.doi.org/10.1590/S1413$\underline{81232007000100025}$

10. Bauman Z. Amor líquido: sobre a fragilidade dos laços humanos. Rio de Janeiro: Jorge Zahar Editor; 2004.

11. Ministério da Saúde (BR). Uso racional de medicamentos: temas selecionados. Brasília; 2012. (Série A. Normas e manuais técnicos).

12. Soler RP, Colet MP, Yahni CZ, Puig AMG. Estabelecimiento de los conocimientos, actitudes e opiniones de la población sobre el uso racional de medicamentos. Aten Primaria. 2015 Jan./Apr.;47(7):446-55. doi: https://doi.org/10.1016/j.aprim.2014.11.001

13. World Health Organization. The rational use of drugs: report of the conference of experts, Nairobi 1985 Jul 25-29. Genebra; 1987.

14. Lopes LMB, Grigoleto ARL. Uso consciente de psicotrópicos: responsabilidade dos profissionais de saúde. Braz J Health. 2011;2(1):1-14.

15. Engelmann A. Dois tipos de consciência: a busca da autenticidade. Psicologia USP. 1997;8(2). doi: http://dx.doi.org/10.1590/S0103-65641997000200003

16. Bauman Z. Vida para consumo, a transformação das pessoas em mercadoria. Rio de Janeiro: Jorge Zahar Editor; 2007.

17. Presidência da República (BR). Casa Civil. Subchefia de Assuntos Jurídicos. Lei nº 8.078, de 11 de setembro de 1990. Dispõe sobre a proteção do consumidor e dá outras providências. DOU [Internet] 1990 set 12 [citado em 2016 jun. 5]. Disponível em: https://goo.gl/ay73uV

18. Governo do Brasil. Definição do termo consumo consciente é ampla; informe-se. Consumir de forma consciente é fundamental para minimizar os impactos negativos que causamos ao meio ambiente [Internet]. Brasília; 2012 [citado em 2016 jun. 3]; Disponível em: https://goo.gl/mE6KF4

19. Bardin L. Análise de conteúdo. Lisboa: Edições 70; 1994.

20. Schenkel EP, Rech N, Farias MR, Santos RI, Simões CMO. Assistência farmacêutica. In: Ministério da Saúde (BR). Saúde no Brasil: contribuições para a agenda de prioridade de pesquisa. Brasília; 2004. (Série B. Textos básicos de Saúde). p. 199-219.

21. Mota MD, Gurgel CS, Cazue SE, Ortún V. Uso racional de medicamentos: uma abordagem econômica para tomada de decisões. Ci Saúde Coletiva. 2008; 13(supl.):589-601. doi: http://dx.doi.org/10.1590/ $\underline{\mathrm{S} 1413-81232008000700008}$

22. Aquino DS. Por que o uso racional de medicamentos deve ser uma prioridade? Ci Saúde Coletiva. 2008;13(supl):733-36. doi: http://dx.doi.org/10.1590/S1413-81232008000700023

23. Soares JCRS, Camargo Junior KR. Autonomia do paciente no processo terapêutico como valor para a saúde. Interface (Botucatu). 2007 jan./abr.;1(21):65-78. doi: http://dx.doi.org/10.1590/S1414$\underline{32832007000100007}$

24. Backes MTS, Meirelles BHS, Fernandes GCM, Rosa LMD, Becker SG, Santos SMDAD. Conceitos de saúde e doença ao longo da história sob o olhar epidemiológico e antropológico. R Enferm Uerj [Internet]. 2009 jan./mar. [citado em 2017 set. 18];17(1):111-17. Disponível em: http://www.facenf.uerj.br/v17n1/ v17n1a21.pdf

25. Gouveia N. Saúde e meio ambiente nas cidades: os desafios da saúde ambiental. Saúde Soc. 1999;8(1):49-61. doi: http://dx.doi.org/10.1590/S0104-12901999000100005 
26. Augusto LGS. Saúde e vigilância ambiental: um tema em construção. Epidemiol Serv Saúde. 2003;12(4):177-87. doi: http://dx.doi.org/10.5123/S1679-49742003000400002

27. Marini S. A estrutura dos glossários do projeto de terminologia da saúde. Acta Scientiarum [Internet]. 2014 [citado em 2017 set. 18];36(2):151-58. Disponível em: https://goo.gl/HRVFkp

28. Cavalcante MDMA, Larocca LM, Chaves MMN, Cubas MR, Piosiadlo LCM, Mazza VAM. Terminologia de enfermagem como instrumento do processo de trabalho do enfermeiro em saúde coletiva. R Esc Enferm USP. 2016;50(4):607-13. doi: http://dx.doi.org/10.1590/S0080-623420160000500010

29. Silva MB, Ribeiro TWHB, Reis CO. O consumo consciente como fator determinante para a propagação da sustentabilidade na sociedade. R Adm Unifatea [Internet]. 2013 [citado em 2017 set. 18]; 5(5):109-124. Disponível em: https://goo.gl/XBs1Fo

30. Lefèvre F. A função simbólica dos medicamentos. R Saúde Púb. 1983;7(6):500-03. doi: https://doi. org/10.1590/S0034-89101983000600007

31. Luz MT. Cultura contemporânea e medicinas alternativas: novos paradigmas em saúde no fim do século XX. Physis. 2005;15(supl):145-76. doi: http://dx.doi.org/10.1590/S0103-73311997000100002

32. Freitas-Santos SG, Marques, IR. Uso dos recursos de internet na enfermagem: uma revisão. R Bras Enferm. 2006;59(2):212-16. doi: http://dx.doi.org/10.1590/S0034-71672006000200017.

33. Huertas MKZ, Campomar MC. Apelos racionais e emocionais na propaganda de medicamentos de prescrição: estudo de um remédio para emagrecer. Ci Saúde Coletiva. 2008;13(supl):651-62. doi: http:// dx.doi.org/10.1590/S1413-81232008000700014

34. Mendonça VS, Menandro MCS. O cuidado com a própria saúde: representações e práticas de futuros profissionais da saúde. R Elect Psicol Pol [Internet]. 2010 [citado em 2017 set. 18];8(22), 116-27. Disponível em: http://www.psicopol.unsl.edu.ar/abril2010 Nota7.pdf

35. Carvalho EV, Ferreira E, Mucini L, Santos C. Aspectos legais e toxicológicos do descarte de medicamentos. R Bras Toxicol [Internet]. 2009 [citado em 2017 set. 18];22(1-2):1-8. Disponível em: http://iah.iec.pa.gov.br/iah/fulltext/lilacs/revbrastoxicol/2009v22n1-2/revbrastoxico2009v22n1-2p1-8.pdf

36. Alvarenga LSV, Nicoletti MA. Descarte doméstico de medicamentos e algumas considerações sobre o impacto ambiental decorrente. R Saúde [Internet]. 2010 [citado em 2017 set. 18];4(3):34-39. Disponível em: http://revistas.ung.br/index.php/saude/article/view/763

37. Melo SAS, Trovó AG, Bautitz IR, Nogueira RFP. Degradação de fármacos residuais por processos oxidativos avançados. Ra Quim Nova [Internet]. 2009 [citado em 2017 set. 18];32(1): 188-97. Disponível em: https://repositorio.unesp.br/handle/11449/25694

38. Nunes B. Fármacos no ambiente: implicações ecotoxicológicas. Captar [Internet]. 2010 [citado em 2017 set. 18];2(1):9-20. Disponível em: https://goo.gl/83PEBS

39. Gasparini AR, Carmo GJ, Frigieri MC. Estudo do descarte de medicamentos e consciência ambiental no município de Catanduva-SP. Ci Tecn [Internet]. 2011 [citado em 2017 set. 18];2(1):38-51. Disponível em: http://citec.fatecjab.edu.br/index.php/files/article/download/10/11

40. Camargo-Borges C, Japu, M. Sobre a (não) adesão ao tratamento: ampliando sentidos do autocuidado. Texto Contexto-Enf. 2008;17(1):64-1. doi: http://dx.doi.org/10.1590/\$0104-07072008000100007

41. Nunes DS. A importância das novas mídias na proteção do meio ambiente em face da crise ambiental. R Elet Curso Dir UFSM. 2013;8:51-9. doi: http://dx.doi.org/10.5902/198136948217

42. Cabral RV, Trevisol FS. A influência da internet na relação médico-paciente na percepção do médico. R AMRIGS [Internet]. 2010 [citado em 2017 set. 18];54(4):416-20. Disponível em: http://www.amrigs. org.br/revista/54-04/010-627 a influencia da.pdf

43. Souza JFR, Marinho CLC, Guilam MCR. Consumo de medicamentos e internet: análise crítica de uma comunidade virtual. R Assoc Méd Bras. 2008;54(3): 225-31. doi: http://dx.doi.org/10.1590/S0104$\underline{42302008000300015}$

44. Silva AX, Cruz EA, Melo V. A importância estratégica da informação em saúde para o exercício do controle social. Ci Saúde Coletiva. 2007;12(3):683-88. doi: http://dx.doi.org/10.1590/S1413$\underline{81232007000300018}$ 
45. Araújo MMT, Silva MJP. Estratégias de comunicação utilizadas por profissionais de saúde na atenção a pacientes sob cuidados paliativos. R Esc Enf USP. 2012;46(3):626-32. doi: http://dx.doi.org/10.1590/ $\underline{\text { S0080-62342012000300014 }}$

46. Fischer $\mathrm{ML}$, Cordeiro $\mathrm{AL}$, Librelato RF. A abstinência voluntária do consumo de carne pode ser compreendida como um princípio ético? Ci Soc Unisinos. 2016;52(1):122-31. doi: http://www.doi. org/10.4013/csu.2016.52.1.14

47. Loures FTR. A implementação do direito à informação ambiental. R Dir Amb [Internet]. 2004 [citado em 2017 set. 18];34:[16 p.]. Disponível em: https://goo.gl/NhQvpa

48. Borelli FC, Hemais MW, Dias PIRC. Ecológicos ou controlados? Construindo discursivamente o consumidor consciente. REMark [Internet]. 2012 [citado em 2017 set. 18];11(2):18. Disponível em: https://goo.gl/ENUwLH

49. Carneiro LA, Porto CC, Duarte SBR, Chaveiro N, Barbosa MA. O ensino da ética nos cursos de graduação da área de saúde. R Bra Educ Med. 2010;34(3):412-21. doi: http://dx.doi.org/10.1590/S0100$\underline{55022010000300011}$

50. Chauhan I, Yasir M, Kumari M, Verma M. The pursuit of rational drug use: understanding factors and interventions. Pharmaspire 2018;10(2):48-4.

51. Jha N, Shankar PR, Anurag M. Effect of an educational intervention on knowledge and perception regarding rational medicine use and self-medication. J Nepal Health Res Counc 2018;16(40):313-20. 